\title{
Availability and utilization of emergency obstetric care public health facilities in Zaria, Northern Nigeria
}

\author{
Ya’u Samira L.*, Tukur Jamilu
}

Department of Obstetrics and Gynecology, College of Health Science, Bayero University Kano, Nigeria

Received: 13 May 2019

Revised: 25 June 2019

Accepted: 16 July 2019

\section{*Correspondence:}

Dr. Ya'u Samira L,

E-mail: sameerahyau@gmail.com

Copyright: (c) the author(s), publisher and licensee Medip Academy. This is an open-access article distributed under the terms of the Creative Commons Attribution Non-Commercial License, which permits unrestricted non-commercial use, distribution, and reproduction in any medium, provided the original work is properly cited.

\begin{abstract}
Background: Maternal mortality rates continue to soar high in Northern Nigeria despite all sorts of interventions being put in place. This has necessitated the need to emphasize on Emergency Obstetric Care (EmOC) to tackle obstetric complications which are the largest direct causes of maternal mortality. The study was conducted to assess the availability of Emergency Obstetric Care facilities in Zaria Local Government Area (LGA) located in Northern Nigeria.

Methods: This was a hospital based cross- sectional descriptive study carried out in Zaria LGA. Data was collected from seven public health facilities using a structured interviewer administered questionnaire.

Results: The LGA met the WHO requirement for the population served while none of the designated BEOC met the UN criteria for such designation. Only $8 \%$ of births took place in the health facilities and $0.7 \%$ of deliveries were by caesarean section. The met need for EmOC in Zaria LGA was $25.1 \%$. Human resources were lacking in number and skills. Some key drugs and equipment needed to carry out signal function were also absent.

Conclusions: Public health facilities in Zaria did not meet the requirements of the United Nations (UN) process indicators. There is need to upgrade the health facilities with the necessary human resource, equipment and facilities to enable them perform their designated EmOC functions.
\end{abstract}

Keywords: Emergency obstetric care, Maternal mortality, Zaria, Northern Nigeria

\section{INTRODUCTION}

Maternal mortality is high globally; about 800 women die from pregnancy and child birth related complications around the world everyday. ${ }^{1}$ Although there has been significant decline globally in recent times, not much progress has been made within sub-Saharan African countries, which have maternal mortality ratios (MMRs) that are rated among the highest in the world. ${ }^{2}$ Nigeria's maternal mortality ratio remains at an unacceptably high level and is considered to be one of the highest in the developing world. $^{3}$ The 2013 Nigeria National Demographic and Health Survey (NDHS) revealed a maternal mortality ratio of (MMR) of 576 per 100000 live births. ${ }^{4}$ In 2010 Nigeria recorded a maternal mortality ratio of 630 deaths per 1000 live births and a lifetime risk of maternal death of 1 in 29 thus ranking her the $10^{\text {th }}$ globally. ${ }^{5}$ Furthermore, estimates have shown that another 1,080000 to 1,620000 Nigerian women and girls suffer every year from disabilities arising from complications of pregnancy and childbirth. ${ }^{6}$

Fifteen percent of pregnant women are expected to develop obstetric complications which in spite of good adequate ante natal services may not be detected. In 1987, the Safe Motherhood programme emphasized the 
importance of access to Emergency Obstetric Care (EmOC) to manage the common causes of obstetric death: hemorrhage, obstructed labor, complications due to unsafe abortion, eclampsia and infection. ${ }^{7}$ Almost all the lives of these women that die could be saved if affordable emergency obstetric care can be made available 24 hours a day, 7 days a week. ${ }^{8}$

EmOC can be described as a set of life saving services that must be available in health facilities to respond to emergencies and complications that arise from pregnancy, delivery and or -postpartum. ${ }^{9}$ EmOC involves particular intervention usually referred to as the signal functions. Based on the ability to perform these functions, facilities are described as basic and comprehensive. Basic Emergency Obstetric Care (BEOC) functions include administration of intravenous antibiotics, intravenous oxytoxics, intravenous anticonvulsants, manual removal of placenta and removal of retained products of conception (with the aid of manual vacuum aspiration), assisted vaginal delivery and basic neonatal resuscitation. They can be performed with basic set of equipment and skills possible in primary health centers and health posts. On the other hand comprehensive emergency obstetric care (CEOC) is restricted to secondary or tertiary facilities. It includes all the basic signal functions in addition to safe blood transfusions and caesarean section.

A set of process indicators were issued by the United Nations International Children Education Fund (UNICEF), World Health Organization (WHO) and United Nations Population Fund (UNFPA) in 1997, which aid in determining the availability, utilization and quality of service. They include the availability of EmOC facilities, proportion of births in EmOC facilities, met needs in EmOC facilities, caesarean deliveries as a proportion of all births and case fatality rate. ${ }^{10}$ The WHO has recommended that for every 500,000 population, there should be availability of four basic emergency obstetric care facilities and one comprehensive obstetric care facility. In addition to the signal functions, the Federal Ministry of Health (FMOH) Nigeria, as part of National Standard for Facilities under a recent maternal mortality reduction initiative has included the 24 hours service operation in facilities and the availability of a minimum of four (4) midwives in each facility. ${ }^{11}$ All pregnant women with complications should have access to and be treated in an EmOC facility.

The minimum recommendation is therefore $100 \%$ of women with complications being treated in EmOC facilities. Also, the United Nations (UN) recommends that at least $5 \%$ of all births should be delivered by caesarean section. ${ }^{12}$ Also the percentage of women who come to the EmOC facility with complications from which they die should not exceed $1 \%$. This will ensure that women who develop complications will have access to the EmOC facilities and will be able to benefit of the optimum care they need. It is not only fair that the facilities should have adequate coverage but that they should also deliver optimum services and be used by those women who need them.

The aim of the study was therefore to assess the availability of EmOC in public health facilities in Zaria LGA.

\section{METHODS}

The study was a cross sectional descriptive study conducted from the $21^{\text {st }}$ of January to $7^{\text {th }}$ of February 2014. The study covered government public health facilities consisting of primary and secondary health facilities in Zaria LGA. Zaria LGA is one of the 23 LGAs in Kaduna state; it comprises of 13 political wards and has a projected population of 502032. The majority are Muslims and Hausa/Fulani whom are mostly farmers. The LGA has numerous health posts, primary health centres and a general hospital. Patients who require more specialized care are often referred to the tertiary center which is the Ahmadu Bello University Teaching Hospital located at Shika.

All facilities that provided maternal health services in the last three months were recruited to form a sample size of 7. Actual status of facilities was determined by the ability of the facility to carry out the Emergency signal functions. Any PHC facility that carried out all the 7 basic signal functions was designated as BEOC. Any secondary facility that carried out all the above basic functions and in addition, blood transfusion and cesarean section was regarded a CEOC. Whereas any PHC or secondary facility short of the above criteria was regarded as a non EmOC (NEOC) facility.

A modified UN's Needs assessment module were used to interview the heads of the facilities for appraisal and to observe for availability of equipments, infrastructure and services. Informed consent was duly sought and the interview was conducted using a pretested structured questionnaire by the authors. The interview focused on obtaining detailed information on availability, utilization and performance of EmOC services. The questionnaire had three sections; the first section was based on facility identification, availability of infrastructure, staffing and maternal health services. The second section focused on summary of deliveries, maternal deaths and obstetric complications in each facility. Available hospital records between $1^{\text {st }}$ of January 2013 and $31^{\text {st }}$ December 2013 were also used. The third section check listed the availability of essential drugs and equipment needed for EmOC. This was done by a room to room physical appraisal of the health facility by the authors.

\section{Statistical analysis}

Questionnaires were checked for completeness and then data was coded and entered into and analyzed with Microsoft Excel spreadsheets. Results were presented in form of tables and charts. 


\section{RESULTS}

The research was conducted in 7 health facilities as shown in Table 1. Six were PHC (BEOC) and 1 was a General Hospital (CEOC).

\section{Performance of signal functions}

Distribution of signal function s according to the WHO and Nigerian guidelines are as shown in Table 1. In the
PHC facilities, only 3 (42.9\%) operated 24 hours services and none of them had at least 4 serving midwives. The secondary facility carried out all the signal functions as per the WHO and FMOH guidelines.

Since none of the primary health facilities met the criteria for designation as BEOC. There is no adequate coverage of BEOC facility (none per 500,000 people).

Table 1: Distribution of signal functions in health facilities in Zaria LGA.

\begin{tabular}{|llll|}
\hline \multirow{2}{*}{$\begin{array}{l}\text { Signal functions } \\
\text { Administration of parenteral antibiotics }\end{array}$} & BEOC N=6, Freq. (\%) & CEOC \\
\cline { 2 - 4 } & Routinely & Last 3 months & N=1, Freq. (\%) \\
\hline Administration of parenteral oxytocic & $6(100.0)$ & $6(100.0)$ & $1(100.0)$ \\
\hline Administration of parenteral anti-convulsant & $6(100.0)$ & $6(100.0)$ & $1(100.0)$ \\
\hline Manual removal of placenta & $3(42.9)$ & $4(57.1)$ & $1(100.0)$ \\
\hline Removal of retained products & $6(100.0)$ & $6(100.0)$ & $1(100.0)$ \\
\hline Assisted vaginal delivery using vacuum/forceps & $2(28.6)$ & $2(28.6)$ & $1(100.0)$ \\
\hline Blood transfusion & $0(0.0)$ & $0(0.0)$ & $1(100.0)$ \\
\hline Caesarean section & $0(0.0)$ & $0(0.0)$ & $1(100.0)$ \\
\hline Four serving midwives & $(0.0)$ & $(0.0)$ & $1(100.0)$ \\
\hline Basic neonatal resuscitation & $0(0.0)$ & $0(0.0)$ & $0(0.0)$ \\
\hline 24 hours service & $5(71.4)$ & $5(71.4)$ & $1(100.0)$ \\
\hline
\end{tabular}

\section{Proportion of births in EmOC facility}

A review of the records showed that a total of 4131 deliveries took place in all the studied health facilities from the $1^{\text {st }}$ January to $31^{\text {st }}$ December 2013. This meant that only $8.12 \%$ of the total expected number of deliveries (19469) in Zaria LGA took place in facilities against the WHO recommended $15 \%$.

\section{Proportion of births by caesarean section}

A review of the records showed that of a total of 4131 deliveries that took place in all the studied health facilities from $1^{\text {st }}$ January to $31^{\text {st }}$ December 2013. Only $3.3 \%$ of the deliveries were through Caesarean section (CS) while $96.7 \%$ were vaginal deliveries. Thus the CS rate for Zaria LGA based on expected deliveries is $0.7 \%$.

\section{Met need for EmOC services}

A total of 734 women presented with obstetric complications. The met need for EmOC facilities is $25.1 \%$.

Hemorrhage accounted for most of the complications $(22.9 \%)$ followed by eclampsia (16.23\%) and prolonged/obstructed labor as well as complications of abortion (5.50\%). Ruptured uterus, sepsis and ectopic pregnancy accounted for $1.70 \%, 1.44 \%$ and $0.79 \%$ of cases respectively (Table 2 ).

Table 2: Pattern of obstetric complications in surveyed facilities.

\begin{tabular}{|lll|}
\hline Complications & Frequency & $\%$ \\
\hline $\begin{array}{l}\text { Haemorrhage (ante/post } \\
\text { partum haemorrhage) }\end{array}$ & 175 & 22.90 \\
\hline Prolonged/obstructed labour & 42 & 5.50 \\
\hline Ruptured uterus & 13 & 1.70 \\
\hline Eclampsia & 124 & 16.23 \\
\hline Sepsis & 11 & 1.44 \\
\hline Complicated abortion & 42 & 5.50 \\
\hline Ectopic pregnancy & 6 & 0.79 \\
\hline Others & 351 & 45.94 \\
\hline Total & $\mathbf{7 6 4}$ & $\mathbf{1 0 0 . 0 0}$ \\
\hline
\end{tabular}

\section{Distribution of maternal deaths}

There were 18 maternal deaths. Fourteen $(77.8 \%)$ of maternal deaths took place in EmOC facility while 4 $(22.2 \%)$ took place in non EmOC facilities.

\section{Availability of functioning equipment}

The secondary facility was observed to have all the labor ward equipments. All (100\%) the PHC had a functional 
sphygmomanometer, thermometer, stethoscope and kidney dish. $83.35 \%$ had artery forceps, cord scissors, stitch scissors, needle holder and urinary urethral catheter as shown in Table 3. Only one PHC had an MVA kit and none of them had vacumn extractors or delivery forceps.

Table 3: Distribution of labor ward equipment in Health facilities in Zaria LGA.

\begin{tabular}{|c|c|c|c|c|c|c|}
\hline \multirow[b]{2}{*}{ Labor ward equipment } & \multicolumn{3}{|c|}{ Primary $(n=6)$} & \multicolumn{3}{|c|}{ Secondary $(\mathrm{n}=1)$} \\
\hline & $\begin{array}{l}\text { AF } \\
\text { Freq. }(\%)\end{array}$ & $\begin{array}{l}\text { ANF } \\
\text { Freq. (\%) }\end{array}$ & $\begin{array}{l}\text { NA } \\
\text { Freq. (\%) }\end{array}$ & $\begin{array}{l}\text { AF } \\
\text { Freq. (\%) }\end{array}$ & $\begin{array}{l}\text { ANF } \\
\text { Freq. (\%) }\end{array}$ & $\begin{array}{l}\text { NA } \\
\text { Freq. (\%) }\end{array}$ \\
\hline Cord clamp & $3(50.0)$ & $0(0.0)$ & $3(50.0)$ & $1(100.0)$ & $0(0.0)$ & $0(0.0)$ \\
\hline Cord scissors & $5(83.3)$ & $0(0.0)$ & $1(16.7)$ & $1(100.0)$ & $0(0.0)$ & $0(0.0)$ \\
\hline Dissecting forceps & $4(66.7)$ & $0(0.0)$ & $2(33.3)$ & $1(100.0)$ & $0(0.0)$ & $0(0.0)$ \\
\hline Artery forceps & $5(83.3)$ & $0(0.0)$ & $1(16.7)$ & $1(100.0)$ & $0(0.0)$ & $0(0.0)$ \\
\hline Vaginal speculum & $2(33.3)$ & $0(0.0)$ & $4(66.7)$ & $1(100.0)$ & $0(0.0)$ & $0(0.0)$ \\
\hline Needle holder & $5(83.3)$ & $0(0.0)$ & $1(16.7)$ & $1(100.0)$ & $0(0.0)$ & $0(0.0)$ \\
\hline Urinary catheter & $5(83.3)$ & $0(0.0)$ & $1(16.7)$ & $1(100.0)$ & $0(0.0)$ & $0(0.0)$ \\
\hline Sphygmomanometer & $6(100.0)$ & $0(0.0)$ & $0(0.0)$ & $1(100.0)$ & $0(0.0)$ & $0(0.0)$ \\
\hline Stethoscope & $6(100.0)$ & $0(0.0)$ & $0(0.0)$ & $1(100.0)$ & $0(0.0)$ & $0(0.0)$ \\
\hline Thermometer & $6(100.0)$ & $0(0.0)$ & $0(0.0)$ & $1(100.0)$ & $0(0.0)$ & $0(0.0)$ \\
\hline Kidney dish & $6(100.0)$ & $0(0.0)$ & $0(0.0)$ & $1(100.0)$ & $0(0.0)$ & $0(0.0)$ \\
\hline Vacuum extractor & $0(0.0)$ & $0(0.0)$ & $6(100.0)$ & $1(100.0)$ & $0(0.0)$ & $0(0.0)$ \\
\hline Wrigley forceps & $0(0.0)$ & $0(0.0)$ & $6(100.0)$ & $1(100.0)$ & $0(0.0)$ & $0(0.0)$ \\
\hline Suction machine & $2(33.3)$ & $1(16.7)$ & $3(50.0)$ & $1(100.0)$ & $0(0.0)$ & $0(0.0)$ \\
\hline Ambu resuscitor & $3(50.0)$ & $0(0.0)$ & $3(50.0)$ & $1(100.0)$ & $0(0.0)$ & $0(0.0)$ \\
\hline Mucus extractor for neonates & $3(50.0)$ & $0(0.0)$ & $3(50.0)$ & $1(100.0)$ & $0(0.0)$ & $0(0.0)$ \\
\hline Oxygen cylinder & $0(0.0)$ & $0(0.0)$ & $6(100.0)$ & $1(100.0)$ & $0(0.0)$ & $0(0.0)$ \\
\hline Stitch scissors & $5(83.3)$ & $0(0.0)$ & $1(16.7)$ & $1(100.0)$ & $0(0.0)$ & $0(0.0)$ \\
\hline Manual vacuum aspiration kit & $2(33.3)$ & $0(0.0)$ & $4(66.7)$ & $1(100.0)$ & $0(0.0)$ & $0(0.0)$ \\
\hline Torch light & $3(50.0)$ & $0(0.0)$ & $3(50.0)$ & $0(0.0)$ & $0(0.0)$ & $1(0.0)$ \\
\hline
\end{tabular}

AF: Available and functioning; NA: Not available; ANF: available and not functioning

Table 4: Distribution of key drugs, anesthesia and consumables in EmOC facility in Zaria LGA.

\begin{tabular}{|lllll|}
\hline \multirow{2}{*}{$\begin{array}{l}\text { Key drug, anaesthesia and } \\
\text { consumable }\end{array}$} & $\mathbf{A}$ & NEOC $(\mathbf{n}=\mathbf{6})$ & $\mathbf{A}$ & CEOC $(\mathbf{n}=\mathbf{1})$ \\
\cline { 2 - 5 } Ergometrine & $2(33.3)$ & $4(66.7)$ & $1(100.0)$ & $0(0.0)$ \\
\hline Oxytocin & $2(33.3)$ & $4(66.7)$ & $1(100.0)$ & $0(0.0)$ \\
\hline Misoprostol & $2(33.3)$ & $4(66.7)$ & $1(100.0)$ & $0(0.0)$ \\
\hline Diazepam & $0(0.0)$ & $6(100.0)$ & $0(0.0)$ & $1(100.0)$ \\
\hline Magnesium sulphate & $0(0.0)$ & $6(100.0)$ & $0(0.0)$ & $1(100.0)$ \\
\hline Anti-biotics & $4(66.7)$ & $2(33.3)$ & $1(100.0)$ & $0(0.0)$ \\
\hline Local anaesthetics & $4(66.7)$ & $2(33.3)$ & $1(100.0)$ & $0(0.0)$ \\
\hline General anaesthetics & $0(0.0)$ & $6(100.0)$ & $1(100.0)$ & $0(0.0)$ \\
\hline Corticosteroids & $2(33.3)$ & $4(66.7)$ & $1(100.0)$ & $0(0.0)$ \\
\hline Analgesic & $4(66.7)$ & $2(33.3)$ & $1(100.0)$ & $0(0.0)$ \\
\hline Adrenalin & $0(0.0)$ & $6(100.0)$ & $1(100.0)$ & $0(0.0)$ \\
\hline Atropine & $0(0.0)$ & $6(100.0)$ & $1(100.0)$ & $0(0.0)$ \\
\hline Calcium gluconate & $0(0.0)$ & $6(100.0)$ & $1(100.0)$ & $0(0.0)$ \\
\hline Antihypertensives & $4(66.7)$ & $4(33.3)$ & $1(100.0)$ & $0(0.0)$ \\
\hline I.V. fluids & $4(66.7)$ & $2(33.3)$ & $1(100.0)$ & $0(0.0)$ \\
\hline I.V. admin set & $4(66.7)$ & $2(33.3)$ & $1(100.0)$ & $0(0.0)$ \\
\hline I.V cannulae & $3(50.0)$ & $3(50.0)$ & $1(100.0)$ & $0(0.0)$ \\
\hline Surgical gloves & $5(83.3)$ & $1(16.7)$ & $1(100.0)$ & $0(0.0)$ \\
\hline Syringes & $5(83.3)$ & $1(16.7)$ & $1(100.0)$ & $0(0.0)$ \\
\hline Suture materials & $3(50.0)$ & $3(50.0)$ & $1(100.0)$ & $0(0.0)$ \\
\hline
\end{tabular}




\begin{tabular}{|c|c|c|c|c|}
\hline $\begin{array}{l}\text { Key drug, anaesthesia and } \\
\text { consumable }\end{array}$ & A & $\begin{array}{l}\text { NEOC }(n=6) \\
\text { NA }\end{array}$ & $\mathbf{A}$ & CEOC $(n=1)$ \\
\hline Sterile gauze & $1(16.7)$ & $5(83.7)$ & $1(100.0)$ & $0(0.0)$ \\
\hline Sanitary pads & $2(33.3)$ & $4(66.7)$ & $0(0.0)$ & $1(100.0)$ \\
\hline Clean drapes & $1(16.7)$ & $5(83.7)$ & $1(100.0)$ & $0(0.0)$ \\
\hline Macintosh/rubber sheet & $3(50.0)$ & $3(50.0)$ & $1(100.0)$ & $0(0.0)$ \\
\hline
\end{tabular}

Table 5: Distribution of laboratory equipment in EmOC facilities in Zaria LGA.

\begin{tabular}{|c|c|c|c|c|c|c|}
\hline \multirow[b]{2}{*}{ Laboratory equipment } & \multicolumn{3}{|c|}{ BEOC $(n=6)$} & \multicolumn{3}{|c|}{ CEOC $(n=1)$} \\
\hline & $\begin{array}{l}\text { AF } \\
\text { Freq. }(\%)\end{array}$ & $\begin{array}{l}\text { ANF } \\
\text { Freq. }(\%)\end{array}$ & $\begin{array}{l}\text { NA } \\
\text { Freq. }(\%)\end{array}$ & $\begin{array}{l}\text { AF } \\
\text { Freq. }(\%)\end{array}$ & $\begin{array}{l}\text { ANF } \\
\text { Freq. }(\%)\end{array}$ & $\begin{array}{l}\text { NA } \\
\text { Freq. }(\%)\end{array}$ \\
\hline Group and Cross match Kit & $2(33.3)$ & $0(0.0)$ & $4(66.7)$ & $1(100.0)$ & $0(0.0)$ & $0(0.0)$ \\
\hline HIV testing kit & $5(83.3)$ & $0(0.0)$ & $1(16.7)$ & $1(100.0)$ & $0(0.0)$ & $0(0.0)$ \\
\hline Hepatitis B testing kit & $1(16.7)$ & $0(0.0)$ & $5(83.3)$ & $1(100.0)$ & $0(0.0)$ & $0(0.0)$ \\
\hline Syphilis testing kit & $0(0.0)$ & $0(0.0)$ & $6(100.0)$ & $1(100.0)$ & $0(0.0)$ & $0(0.0)$ \\
\hline Centrifuge and test tubes & $0(0.0)$ & $0(0.0)$ & $6(100.0)$ & $1(100.0)$ & $0(0.0)$ & $0(0.0)$ \\
\hline Microscope & $1(16.7)$ & $0(0.0)$ & $5(83.3)$ & $1(100.0)$ & $0(0.0)$ & $0(0.0)$ \\
\hline Bacteriological test kit & $0(0.0)$ & $0(0.0)$ & $6(100.0)$ & $1(100.0)$ & $0(0.0)$ & $0(0.0)$ \\
\hline $\begin{array}{l}\text { Haemoglobinometer for } \\
\text { haematocrits }\end{array}$ & $5(83.3)$ & $0(0.0)$ & $1(16.7)$ & $1(100.0)$ & $0(0.0)$ & $0(0.0)$ \\
\hline Urinalysis test kits & $5(83.3)$ & $0(0.0)$ & $1(16.7)$ & $1(100.0)$ & $0(0.0)$ & $0(0.0)$ \\
\hline Malaria test kit & $5(83.3)$ & $0(0.0)$ & $1(16.7)$ & $1(100.0)$ & $0(0.0)$ & $0(0.0)$ \\
\hline Equipment for full blood count & $1(16.7)$ & $0(0.0)$ & $5(83.3)$ & $1(100.0)$ & $0(0.0)$ & $0(0.0)$ \\
\hline Blood bank refrigerator & $0(0.0)$ & $0(0.0)$ & $6(100.0)$ & $1(100.0)$ & $0(0.0)$ & $0(0.0)$ \\
\hline
\end{tabular}

AF: Available and functional; ANF: Available and non-functional; NA: Not available.

Table 6: Distribution of health workers by level of care in ZARIA LGA.

\begin{tabular}{|lll|}
\hline Health worker & Facility EOC status & \\
\hline Obstetrician & NEOC $(\mathbf{n = 6})$ Freq. & CEOC $(\mathbf{n = 1})$ Freq. \\
\hline Doctors/non specialist & $0(0.0)$ & $1(100.0)$ \\
\hline Nurse/midwife & $0(0.0)$ & $1(100.0)$ \\
\hline Midwife only & $5(83.3)$ & $1(100.0)$ \\
\hline Nurse only & $0(0.0)$ & $1(100.0)$ \\
\hline Community health extension worker & $3(50.0)$ & $1(100.0)$ \\
\hline Anaesthiologist & $6(100.0)$ & $0(0.0)$ \\
\hline Theatre nurse & $0(0.0)$ & $1(100.0)$ \\
\hline
\end{tabular}

Table 4 shows that none of the PHCs had anti convulsants with $83.3 \%$ having syringes and surgical gloves. Only $66.7 \%$ had IV fluids/administration set, analgesics, antibiotics and local anaesthetics. In the secondary facility, all the key drugs and consumables were available apart from the anti-convulsants and sanitary pads.

The secondary facility had all the laboratory equipment which was functional as well. About eighty percent of the PHCs had the HIV test kit, haemoglobinometer, urinalysis test kit, and Malaria test kits as shown in Table 5.
Table 6 shows that only the CEOC facility had all the required staffing and all the BEOC facilities had a community health extension worker.

No BEOC had a doctor or Obstetrician. Only 3 BEOC had Nurse only and 5 BEOC had Nurse /Midwife.

All the facilities had referral forms (100\%) and functional transport facilities (community volunteer transport) to support referral (100\%) but there was no availability of a functional 2-way referral system and only one facility had communication facility to support referral. 


\section{DISCUSSION}

After the assessment based on the WHO guidelines it was observed that the availability of EOC facilities in Zaria LGA is inadequate which is similar to the findings of various studies carried out in Lagos, Uganda, Osun and Kaduna states in Nigeria where the recruited facilities did not meet the UN requirements as well. ${ }^{12-15}$

The secondary facility had the necessary staff but not in adequate numbers. Amongst the PHCs, $83.3 \%$ of the facilities had Nurse/Midwives and senior health extension workers in contrast to a study done in DCR where only five out of the nine hospitals had formally trained NurseMidwife. ${ }^{16}$ The staffing shortage may largely be attributed to the poor welfare and working conditions at the primary and secondary levels thus prompting health workers to seek greener pastures elsewhere.

There were varying amounts of the key drugs, equipment and supplies available in the health facility. The commonest drugs available at the PHCs were the antibiotics, anti-hypertensive and analgesics. Oxytocics were available only in $33.3 \%$ of facilities as similar to the findings in Bangladesh where less than half of the facilities had oxytocics. ${ }^{17}$ The low numbers of facilities with oxytocics and the absence of magnesium sulphate in all the facilities is note worthy bearing in mind that postpartum haemorrage (which is prevented by the use of oxytocics) and eclampsia (which is prevented and treated by magnesium sulphate) are some of the commonest causes of maternal mortality in Nigeria. Lack of drugs and other consumables implies purchase out of facility which will lead to delay in receiving treatment. Higher costs of these items outside the facilities may impede treatment for poorer clients too.

Vacuum extractors and delivery forceps which are core for carrying out signal functions were unavailable in most PHCs. This has prevented the classification of some PHC facilities as BEOC facilities despite carrying out all other signal functions. Considerably absent too are Manual Vacuum Aspiration kits which are core for carrying some signal functions. Only two facilities had them despite the availability of a good number of health workers who had undergone training on carrying out manual vacuum aspiration. These findings are similar to those of the study in Gambia where only $17 \%$ and $24 \%$ of facilities had vacuum extractors and MVA kits. ${ }^{18}$

The most performed signal functions were administration of parenteral antibiotics and oxytocics and basic neonatal resuscitation. This finding is similar to a study carried out in Peru and Nicaragua. ${ }^{19}$ The least performed was manual removal of retained products while assisted vaginal delivery was not carried out at all in any of the PHCs. The non-performance of these signal functions in the PHCs was largely due to lack of equipment and necessary training. Most cases were referred to the secondary facility thereby adding more strain to the facility when it could have been easily carried out at the PHC which is suppose $d$ to serve as a BEOC. This finding is not farfetched from that of a study carried out in Nepal where none of the neither public nor private facilities qualified as a BEOC. ${ }^{21}$

A total of 4131 births took place in the recruited facilities under the year in review. Despite the provision of free maternal services to women by the state there are still fewer births in the health facilities. This is typical of predominant Hausa/Fulani communities because most women practice "purdah" and health decision making is often made by the men. This makes a lot of women to have their babies at home, if their husbands are absent or if they don't approve of hospital births. It was observed that unfortunately only $8.12 \%$ of the births took place in the EmOC facility which is far-fetched from the recommended $15 \%$. This finding though low is way higher than that of a study in Sierra Leone where only $2 \%$ of births took place in an EOC facility, but quite lower than that of a study in Gambia, where over $62 \%$ of births took place in EmOC facilities in all the health divisions. ${ }^{18,21}$ Nevertheless since only public facilities were studied, some births may have taken place in private facilities which tend to be more EmOC competent.

Only $3.3 \%$ of the deliveries was through caesarean section which is below the WHO recommended minimum of $5 \%$. This value is way lower than those obtained in urban Kenyan facilities (although below recommended level) which were $3.7 \%$ and $4.5 \%$ in 2008 and 2009 respectively. ${ }^{22}$ This is an indication that many women who are in dire need of the operative services were not getting it and would thus contribute to the high MMR. This low proportion may be attributed to the fact that the secondary facility has only one Nurse Anesthetist and one peri-operative Nurse as well who work round the clock to provide operative services. This lack of staffing will definitely limit the number of $\mathrm{C}$-sections that will be provided. The presence of a University Teaching hospital nearby may also contribute to low CS rates in the secondary facility as most clients will prefer to go to the tertiary institution for more improved and specialized care.

A total of 18 maternal deaths were recorded in the recruited facilities under the year of review. Most of the facilities did not record the cause of the death. A total number of 764 obstetric complications were recorded and treated in the facilities. Most of the PHCs had no sufficient record of obstetric complications.

The met need of $25 \%$ which is just about a quarter of the recommended $100 \%$ contrasts to that of a study in Sierra Leone where only one province out of four had a met need of over $10 \% .{ }^{21}$ This shows that most women with obstetric complications were not getting the right care and that the EmOC services were being underutilized. This could be due to the rather poor quality of care available which may make clients resort to private 
facilities or the tertiary center thus making it overcrowded. The studied facilities however could be improved upon if the government pays attention to them and provide all the necessary human resource, facilities and medications.

After the assessment, it was found out Zaria LGA did not meet the WHO requirements for the availability of 4 BEOC facilities per 500,000 people, but met the requirement for 1 CEOC per 500,000 people. Only $8.12 \%$ of the births were estimated to have taken place in EmOC facilities and the proportion of births that took place through C-section were $0.7 \%$. The estimated met need for EmOC facilities was $25.1 \%$. Unfortunately the case fatality rate for EmOC facilities could not be calculated due to inadequate data on maternal deaths. Human resources were lacking in number and in skills as well in both PHCs and the secondary facilities. The availability of key drugs and equipment required for the performance of signal functions were grossly inadequate in the PHCs.

\section{CONCLUSION}

Urgent steps need to be taken in order to address the poor state of EmOC facilities in Zaria LGA. Training of health workers especially Nurses/Midwives on the performance of assisted vaginal delivery and manual removal of retained products should be done. Procurement of the vacuum extractors/Wrigley's forceps for assisted vaginal delivery as well as Manual vacuum aspiration kits for removal of retained products should be made for all facilities. More skilled birth attendants should be recruited to cater for maternal needs so as to ensure 24 hours services. All key emergency obstetric drugs and other necessary supplies should be readily available to prevent delays arising from procurement out of health facilities. There is a need to improve record keeping in terms of completeness and accuracy. Also the National Health Information Management system should upgrade facility record forms to include records of all direct obstetric complications and causes of maternal death. Health workers especially at the secondary level need to be sensitized on the importance of referral and communications facilities for supporting referral should be readily available to minimize delays. More Theater staffs at the secondary levels need to be recruited to ensure 24 hours surgical services in adequate numbers so as improve the lifesaving services.

Funding: No funding sources

Conflict of interest: None declared

Ethical approval: The study was approved by the Institutional Ethics Committee

\section{REFERENCES}

1. World Health Organization: The world health reports; make every woman and child count. Geneva; 2005:61-62. http://www.who.int/whr/2005/en. Accessed on $14^{\text {th }}$ August 2008.

2. Lozano R, Wang H, Foreman KJ, Rajaratnam JK, Naghavi M, Marcus JR, et al. Progress towards Millennium Development Goals 4 and 5 on maternal and child mortality: an updated systematic analysis. Lancet. 2011;378(9797):1139-65.

3. Harrison KH. The Struggle to reduce high maternal mortality in Nigeria. Afr J Reprod Health. 2009;13(3):9-20.

4. National Population Commission Nigeria and ICF international. Nigeria Demographic and Health Survey 2013. Abuja Nigeria: NPC and ICF International. 2014:273

5. WHO, UNICEF, UNFPA, World Bank. Trends in maternal mortality: 1990 to 2010. Geneva; 2010. Available at: http://www.who.int/reproductive health/publications/monitoring/9789241503631/en/. Accessed on $12^{\text {th }}$ December 2012.

6. Fabamwo AO, Okonofua FE. An assessment of policies and programs for reducing maternal mortality in lagos state, Nigeria. Afr J Reprod Health. 2010;14(3):55.

7. Maine D, Rosenfield A. The safe motherhood initiative. Why has it stalled? American Journal of Public Health. 1999;89:480-2.

8. United Nation's Population Fund. Emergency obstetric care: checklist for planners. New York; 2003.

9. Lobis S. Fry D. Paxton A. Program note: applying the UN process indicators for emergency obstetric care to the United States. Int $\mathbf{J}$ Gynecol Obstet. 2005;88:203-7.

10. Maine D. Guidelines for monitoring the availability and use of Obstetric services. $2^{\text {nd }}$ ed. New York: UNICEF/WHO/UNFPA; 1997. Available at: http://www.popline.org/node/279682. Accessed on $27^{\text {th }}$ November 2013.

11. Federal Ministry of Health FMOH and UNFPA: National study on essential obstetric facilities in Nigeria. 2003. Available at: http://www.nigeria.unfpa.org/document/eoc.doc. Accessed on 10th March 2013.

12. Douangphachanh $\mathrm{X}$, Ali M, Outavong $\mathrm{P}$, Alongkon P, Sing M, Chushi K. Availability and use of emergency obstetric care services in public hospitals in laos PDr: a systems analysis. Laos: Bioscience Trends. 2010;4(6):318-24.

13. Mboye AK, Asimwe JB, Kabarangira, Nanda G, Orinda V. Emergency obstetric care as the priority intervention to reduce maternal mortality in uganda. Kampala. Int J Gynecol Obstet. 2007;96:220-5.

14. Ijadunola KT, Fatusi AO, Orji EO, Adeyemi AB, Owolabi OO, Ojofeitimi EO, et al. Unavailability of essential obstetric care services in a local government area of South-West Nigeria. J Health Popul Nutr. 2007;25:94-100.

15. Odogwu K, Audu O, Baba-Lafia S, Bawa U, Tukur B, Ejembi C, et al. Availability and utilization of emergency obstetric care services in three 
communities in Kaduna State, Northern Nigeria. Kaduna. Afr J Reprod Health. 2010;2(4):55-60.

16. Casey SE, Mitchell KT, Amisi IM, Haliza MM, Aveledi B, Kalenga $\mathrm{P}$, et al. Use of facility assessment data to improve reproductive health services delivery in the democratic republic of the Congo. Congo: Conflict Health J. 2009;3(12):1-5.

17. Anwar I, Kalim N, Koblinsky M. quality of obstetric care in public sector facilities and Constraints to implementing emergency obstetric care service: evidence from high and low performing districts of Bangladesh. J Health Popul Nutr. 2009;27(2):139-55.

18. Ministry of Health and Social Welfare, UNFPA, UNICEF, WHO, AMDD. National Assessment for Emergency Obstetric and Newborn Care. The Gambia: UNFPA; 2012. Available at: http://www.gambia.unfpa,org/en/publications.

Accessed on $18^{\text {th }}$ October 2013.

19. Bailey P, Paxton A, Lobis S, Fry D. The availability of life saving Obstetric services in developing countries: an in-depth look at the signal functions for Emergency Obstetric Care. New York: Int J Gynecol Obstet. 2006;93:285-91.
20. Department of Community Medicine and family health institute of Medicine Kathmandu. Final report: study on utilization of Emergency Obstetric care in selected districts of Nepal. Kathmandu: FHD: 2004:2.

21. Oyerinde K, Yvonne H, Amara P, Kanu R, Shoo R, Daoh K. The status of maternal and newborn care services in Sierra Leone, 8 years after ceasefire. Int $\mathbf{J}$ Gynecol Obstet. 2011;114(2):168-73.

22. Echoka E. Existence and functionality of emergency obstetric care services at district level in Kenya: theoretical coverage versus reality. BMC Health Serv Res. 2013;13:113.

Cite this article as: Ya'u Samira L, Jamilu T. Availability and utilization of emergency obstetric care public health facilities in Zaria, Northern Nigeria. Int J Reprod Contracept Obstet Gynecol 2019;8:3535-42. 